\title{
Investigation of the Applicability of a Two-Motor Concept for Public Transportation Systems
}

\author{
Sebastian Sigle \\ Institute of Vehicle Concepts \\ German Aerospace Center (DLR) \\ Pfaffenwaldring 38-40 \\ D-70569 Stuttgart, Germany \\ ORCID: 0000-0003-1533-2043
}

\author{
Fabius Epple \\ Institute of Vehicle Concepts \\ German Aerospace Center (DLR) \\ Pfaffenwaldring 38-40 \\ D-70569 Stuttgart, Germany \\ Email: fabius.epple@dlr.de
}

\author{
Patrick Dongus \\ Institute of Vehicle Concepts \\ German Aerospace Center (DLR) \\ Pfaffenwaldring 38-40 \\ D-70569 Stuttgart, Germany \\ Email: patrick.dongus@dlr.de
}

\begin{abstract}
A common approach to enhance the overall efficiency of an electric driven vehicle is to use a double motor concept. In the hereby presented research project TIOM (Two In One Motor) two different electric motors are used for traction, the compressor of the air conditioning (AC) system and the air compressor for the pneumatic systems in a public bus used in urban and suburban traffic. The main research questions in the following paper are first how the TIOM concept can be adapted to urban busses and second if the developed operation strategy leads to higher efficiencies. For this purpose a use case was defined and modelled with Dymola. A typical driving cycle was defined as use scenario. The model contains an operation strategy that can select between $\mathbf{1 6}$ different operation modes for the two motors based on the efficiencies of the motors, the torque requirements, the rotation speed of the wheel and the rotation speed range of the compressors. As a result, the energy consumption for the use case is evaluated and compared to a bus with a conventional motor concept with one large motor.
\end{abstract}

Keywords-energy, highly integrated drives, two in one motor concepts, simulation, Dymola, Modelica, heavy duty applications, public transport

\section{INTRODUCTION}

The motivation and the basic idea of the TIOM concept were already introduced in [1] and [2]. In figure 1 the current topology of the TIOM concept for a typical battery electric vehicle (BEV) containing two motors on one common shaft for traction, the Air conditioning (AC) compressor and the related power electronics $(\mathrm{PE})$ is compared to a conventional system with two separate motors. Two clutches allow to engage or disengage the two motors from the shaft. One motor (EM I) has a higher power rating than the other (EM II) and so the idea behind it is to operate every motor in its best efficiency point, depending on the applied load. Also a boost mode that uses both motors together is considered. Therefore both motors, the drive shaft and the compressor of the AC circuit can be coupled in different ways by using two clutches.

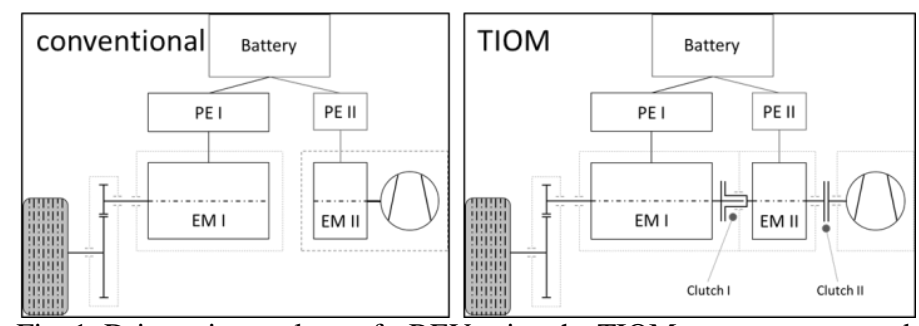

Fig. 1: Drivetrain topology of a BEV using the TIOM concept compared to a conventional drivetrain

A basic electric design of the two motors was already done in [3]. Therefore two basic operation modes have been used to determine the energy reductions of this concept without respect to the AC circuit. In [4] a simulation model containing the AC circuit and a control strategy with ten different operation modes was built to determine the energy reduction potential for this case. In [5] the TIOM concept was adapted to a refuse collection vehicle, where the second drive unit was the hydraulic system instead of the AC system. In this paper the TIOM concept is adapted to a public service bus. The methodical approach is visualized in figure 2 based also on the enumeration of the following chapters. In a first step the drivetrains, that are available on the market, have been evaluated regarding their feasibility for double motor concepts. Also the different auxiliary drives have been analyzed. Based on these outcomes a reference architecture of the drivetrain including the auxiliary drives is determined by conducting a benefit analysis. In a further step a use case containing a reference scenario and vehicle concept is defined. Considering the previous assumptions, a model of the vehicle containing the relevant systems is developed. Furthermore an operation strategy is including several operation modes is defined and implemented in the model. Aiming to find the most efficient parameter set a parameter variation is conducted. 


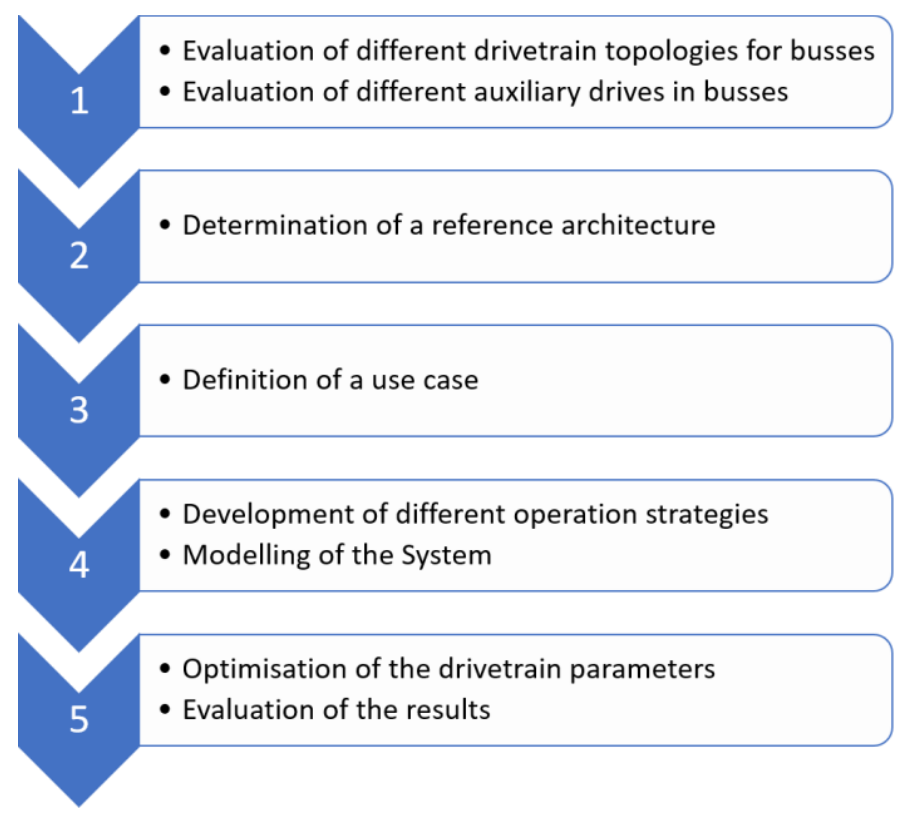

Fig. 2: methodical approach with chapter enumeration

For the following evaluation only busses for public transport in urban and suburban areas have been considered. The denomination of the different types of busses in Germany is given in Table 1, together with typical lengths and the amount of stock of German bus operators in 2019 [6] [7].

TABLE 1: DENOMINATIONS OF PUBLIC BUSSES IN GERMANY

\begin{tabular}{|c|c|c|}
\hline Designation & Length [m] & Stock 2019 \\
\hline Minibus & $6-8$ & 338 \\
\hline Midibus & $8-10$ & 236 \\
\hline Standard bus & 12 & 10660 \\
\hline Double decker bus & $12-13.7$ & 354 \\
\hline Large capacity bus & 15 & 272 \\
\hline Articulated bus & 18 & 8072 \\
\hline
\end{tabular}

In common electrical busses two different drivetrain assemblies can be found. One is the drivetrain with a portal axis system with one motor for each wheel. Either with wheel hub motor or with motors close to each wheel. An example for a wheel hub motor is Ziehl-Abegg ZAwheel. Another example for close wheel motors is ZF AVE 130, which is already in use in Mercedes-Benz eCitaro busses [8]. Another drivetrain solution is the central motor with one motor in the middle that propels one axis with both wheels. An example for this is the ZF CeTrax system [9] which is currently used in the bus Urbino 15 LE electric from the bus manufacturer Solaris.

In a typical bus the following auxiliary components, that are also part of the bus energy system, can be found:

- HVAC-System: typically electrical power ratings between 8 and $14 \mathrm{~kW}$ are installed to heat up and cool down the cabin.
- Air compressor: compressed air is used for several pneumatic actors in a bus like the door drive, pneumatic braking system, and air suspension including kneeling function. Typically the air compressor works in interval operation to keep the air pressure between 8 and 12 bar and has mechanical power ratings from 3 to $6 \mathrm{~kW}$.

- Power-steering pump: to support the driver a hydraulic steering system is used. The needed power is dependent on the driving situation and rises up to $4 \mathrm{~kW}$ electric.

\section{ARCHITECTURE DETERMINATION}

Based on these outcomes a reference architecture is determined. Concerning the drivetrain assembly it is evident that the TIOM concept is only suitable with a central motor concept. The assembly space would not be sufficent in a portal axis architecture.

Concerning the auxiliary drives a benefit analysis was conducted to evaluate which combination of auxiliary drives fits best to be integrated into the TIOM concept. The following assumptions have been made:

- Only the AC system is regarded, the heating system is not relevant. The electric AC compressor is working continuously.

- The Air compressor is working in interval mode to ensure a defined pressure level in the compressed air reservoir.

- The power-steering pump is working on-demand, which is mainly depended on the steering angle and the speed.

Based on experiences in previous works the following parameters have been identified as beneficial for the TIOM concept. Using a scoring system the below cited parameters have been evaluated for different combination of traction and auxiliary drives, which is shown in figure 3 with the same enumeration. The scoring value differs from 1 (lowest beneficial) to 5 (highest beneficial). The auxiliaries are designed as AC (air conditioning), Air (air compressor) and PSP (power-steering pump).

1) a high power ratio between installed traction and auxiliary power ratings

2) giving high power requests on EMII during driving

3) giving high power requests on EMII during standstill

4) low load fluctuations of EMII during operation of EMII

5) easy feasibility of the control system like the predictability of load requests 


\begin{tabular}{|c|c|c|c|c|c|c|}
\hline auxiliary drives & $\mathbf{1}$ & $\mathbf{2}$ & $\mathbf{3}$ & $\mathbf{4}$ & $\mathbf{5}$ & $\boldsymbol{\Sigma}$ \\
\hline AC, Air & 4 & 4 & 4 & 4 & 4 & $\mathbf{2 0}$ \\
\hline AC & 3 & 3 & 3 & 5 & 5 & $\mathbf{1 9}$ \\
\hline AC, Air, PSP & 5 & 5 & 4 & 3 & 1 & $\mathbf{1 8}$ \\
\hline AC, PSP & 4 & 4 & 3 & 2 & 2 & $\mathbf{1 5}$ \\
\hline Air & 1 & 2 & 2 & 3 & 3 & $\mathbf{1 1}$ \\
\hline Air, PSP & 2 & 3 & 2 & 2 & 1 & $\mathbf{1 0}$ \\
\hline PSP & 1 & 2 & 1 & 2 & 1 & $\mathbf{7}$ \\
\hline
\end{tabular}

Fig. 3: Evaluation matrix of the benefit analysis

The power ratio rises with a higher number of auxiliaries. As the AC compressor has a significantly higher power rating than the other auxiliaries, the variants with the AC compressor included have the highest scoring in 1). The same effect can be seen when regarding the power requests of EMII during driving in 2). During standstill, only the AC and air compressors are active, the power-steering pump is not active. This has a significant effect on the power requests of EMII during standstill in 3). Also has the power-steering pump higher load fluctuations and is not deterministic as it is driven on demand, which yields to a lower value in 4) and 5). Summarizing all up it turned out, that the combination of air condition compressor an air compressor is assumed to have the highest potential for being integrated into the TIOM concept. The determined reference architecture is visualized in figure 4 . The two electric motors are arranged on one shaft and connected to one Drive power converter each. The compressor of the AC system and the air compressor are connected via a clutch so they can be engaged and decoupled. Therefore the operating system has to control three clutches.

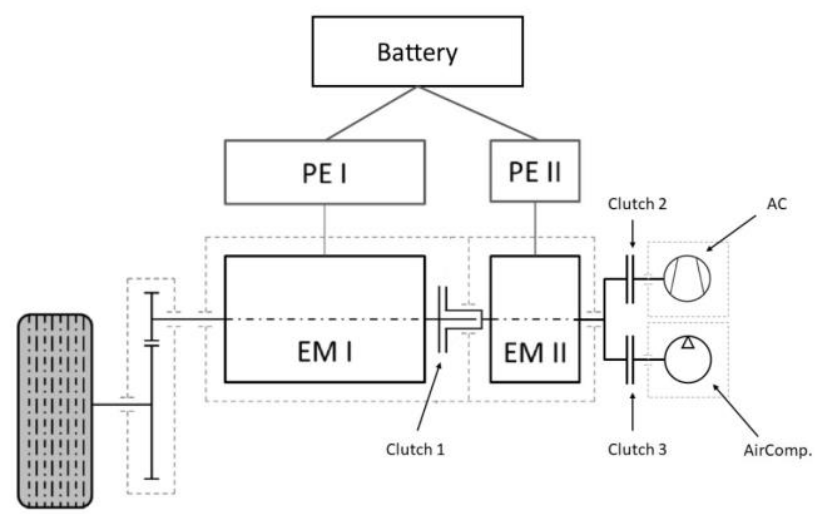

Fig. 4: System architecture of reference vehicle

\section{USE CASE}

In the next step a use case was defined with the previous introduced architecture. The use case is an electric public service bus with 3 doors with a pneumatic drive, a pneumatic braking system and pneumatic chassis. Following the data in chapter I a standard bus was determined to be the use case as this bus types represents $53 \%$ of the busses in Germany. Based on typical values of these busses the vehicle parameter set was defined according to Table 2. This parameter set is used for the estimation of the drivetrain parameters which is conducted by a simulation of the longitudinal dynamics.

TABLE 2: VEHICLE PARAMETERS

\begin{tabular}{|c|c|c|}
\hline parameter & unit & value \\
\hline vehicle mass & {$[\mathrm{kg}]$} & 19.500 \\
\hline Rolling resistance coefficient & {$[-]$} & 0.01 \\
\hline front area & {$\left[\mathrm{m}^{2}\right]$} & 7.5 \\
\hline drag coefficient & {$[-]$} & 0.5 \\
\hline rotational inertia factor & {$[-]$} & 1.1 \\
\hline efficiency axle drive & {$[-]$} & 0.95 \\
\hline
\end{tabular}

To gain a reference scenario, the driving cycle "SORT 2" of the International Association of Public Transport (UITP) [10] was used. The three SORT cycles were created to compare the energy consumption of busses in urban and suburban areas based on data of real bus journeys, so that the use of these cycles leads to energy consumption values that are comparable to real ones. Basically the SORT cycle consists of different velocity-trapezoids that represents typical situations. They have been designed in a way that the operation points draw the same pattern as in measured real operations. Between the trapezoids there are stops, that should represent standstill periods due to waiting times in urban traffic. At the end of the cycle an additional stop time is defined, that should represent a bus station. SORT1 should represent urban, SORT3 suburban bus traffic. SORT2 should characterize a mixture of both. By evaluating typical average bus velocities in Germany it turned out that SORT2 fits best to German urban bus conditions. The velocity profile of the SORT2 cycle is shown in figure 5 .

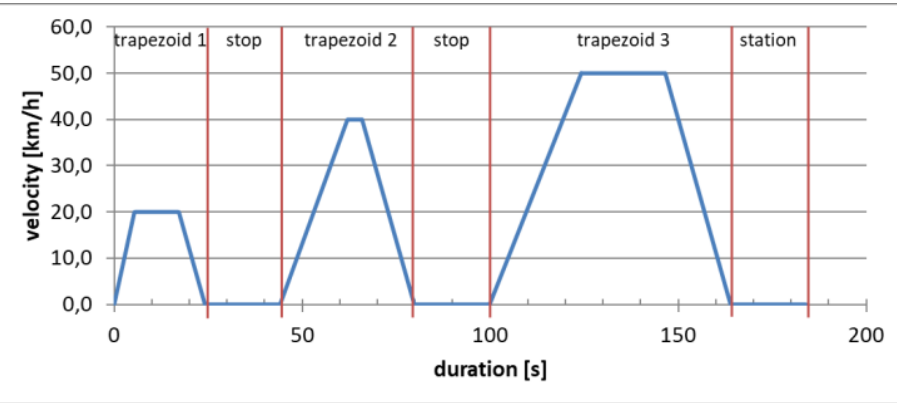

Fig. 5: Bus driving cycle SORT2

Using the data from Table 2 and figure 5 the drivetrain parameters have been determined by conduction some calculations. These parameters are listed in Table 3. It turned out that a total electric motor power of $230 \mathrm{~kW}$ is 
necessary to fully meet the requirements of the traction and the auxiliary drives. This includes the assumption that the air compressor is only working during braking or standstill. For an initial approach it was assumed that EMII should be able to provide enough power for the AC system and the traction when driving with $60 \mathrm{~km} / \mathrm{h}$ continuously, which is the highest allowed velocity for busses in Germany. This yields to a power rating of $60 \mathrm{~kW}$ for EMII and therefore $170 \mathrm{~kW}$ for EMI. The characteristic parameters are also shown in Table 3. Characteristic diagrams with a slightly other configuration can be seen in figure 11 and figure 12. Due to a parameter optimization the power ratings have been changed to $190 \mathrm{~kW}$ and $40 \mathrm{~kW}$, therefore the characteristic diagrams have been scaled.

TABLE 3: DRIVETRAIN PARAMETERS

\begin{tabular}{|c|c|c|}
\hline parameter & unit & value \\
\hline initial power rating EMI & {$[\mathrm{kW}]$} & 170 \\
\hline max. torque EMI & {$[\mathrm{Nm}]$} & 612 \\
& & \\
\hline max. rotational speed EMI & {$[1 / \mathrm{min}]$} & 12,000 \\
\hline initial power rating EMII & {$[\mathrm{kW}]$} & 60 \\
\hline max. torque EMII & {$[\mathrm{Nm}]$} & 216 \\
\hline max. rotational speed EMII & {$[1 / \mathrm{min}]$} & 12,000 \\
\hline gear ratio wheel & {$[-]$} & 33.28 \\
\hline air compressor power rating & {$[\mathrm{kW}]$} & 4,000 \\
\hline air compressor rotational speed range & {$[1 / \mathrm{min}]$} & $1,000-3,500$ \\
\hline gear ratio air compressor & {$[-]$} & 2.75 \\
\hline AC compressor & {$[\mathrm{kW}]$} & 5,400 \\
\hline AC compressor rotational speed range & {$[1 / \mathrm{min}]$} & $500-3,500$ \\
\hline gear ratio AC compressor & {$[-]$} & 3.16 \\
\hline
\end{tabular}

The gear ratio was defined considering the maximum velocity of busses with $60 \mathrm{~km} / \mathrm{h}$ and the maximum rotational speed of the motors with 12,000 rpm. Also the air compressor and the AC compressor have gears. It was preferred, that the air compressor and the AC compressor could be connected to the same shaft as the wheels as often as possible. Hence the ranges of the rotational speeds of air compressor and AC compressor have adapted to the range of the motors as good as possible.

\section{MODELLING}

A model of the vehicle was created with the simulation software Dymola to evaluate the energy consumption of the reference vehicle in the reference cycle. At the DLR Institute of vehicle concepts a new basic model for automotive vehicles was introduced to easily adapt new architectures. Based on this model with a typical electric drivetrain the TIOM concept was modelled as it can be seen in figure 6. It contains the drive cycle (1), the longitudinal dynamics (2), a control strategy (3), clutches (4), an air compressor (5), an AC compressor (6), EMI (7), EMII (8), PEI (9), PEII (10), a battery (11), an evaluation block (12), environment conditions (13), simulation parameters block (14) and auxiliaries (15). The whole system was modelled in a slim design to get faster simulations.

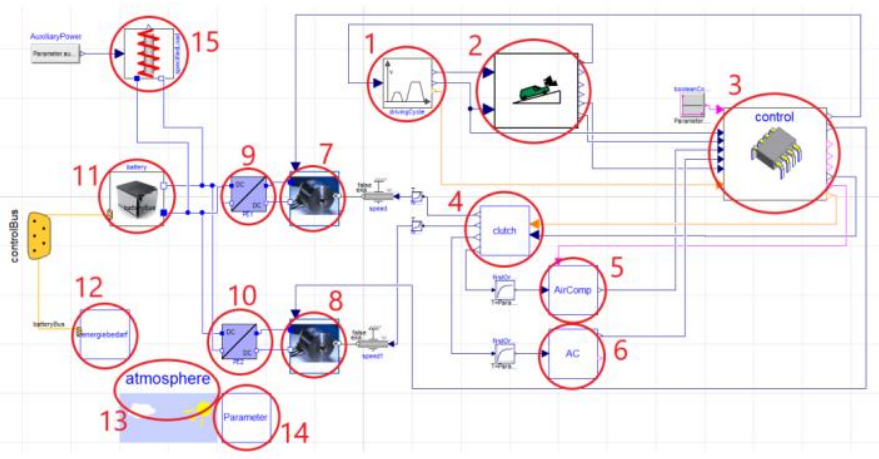

Fig. 6: Simulation model of the reference vehicle

The crucial point was to define and implement an operation strategy that maximizes the overall efficiency by operating both motors in their best efficiency points. Therefore 16 operation modes have been defined, that control the motors and the clutches. These modes have been visualized in the operation strategy matrix in figure 7. Therein EMI and EMII, the air compressor (Air) and the $\mathrm{AC}$ compressor (AC) are designated to be active (on) or not active (off). The three clutches $(\mathrm{C} 1, \mathrm{C} 2, \mathrm{C} 3)$ are designated to be opened $(\mathrm{O})$ or closed $(\mathrm{C})$. In the matrix it was distinguished between activated (lower half) or deactivated (upper half) AC system.

\begin{tabular}{|c|c|c|c|c|c|c|c|}
\hline Mode & EM1 & EM2 & C1 & C2 & C3 & AC & Air \\
\hline Off & off & off & O & O & O & off & off \\
\hline EM1 & on & off & O & O & O & off & off \\
\hline EM2 & off & on & C & O & O & off & off \\
\hline Boost & on & on & C & O & O & off & off \\
\hline EM1 + AirComp. & on & off & C & O & C & off & on \\
\hline EM2 + AirComp. & off & on & C & O & C & off & on \\
\hline Boost + AirComp. & on & on & C & O & C & off & on \\
\hline Off + AirComp. & off & on & O & O & C & off & on \\
\hline EM1 + AC & on & off & C & C & O & on & off \\
\hline EM1 + AC + AirComp. & on & off & C & C & C & on & on \\
\hline EM2 + AC & off & on & C & C & O & on & off \\
\hline EM2 + AC + AirComp. & off & on & C & C & C & on & on \\
\hline Boost + AC & on & on & C & C & O & on & off \\
\hline Boost + AC + AirComp. & on & on & C & C & C & on & on \\
\hline Off + AC & off & on & O & C & O & on & off \\
\hline Off + AC + AirComp. & off & on & O & C & C & on & on \\
\hline
\end{tabular}

Fig. 7: Operation strategy matrix

It was assumed that the $\mathrm{AC}$ system is either working with a continuous electrical power request that is dependent on the ambient temperature or is deactivated. The air compressor has an own operation strategy. It works in interval operation to ensure a pressure level between 8 to 12 bar in the compressed air reservoir. The 
pressure inside this reservoir is modelled with thermodynamic equations. Several operations lead to a pressure loss, i.e. door opening/closing at stations, braking system, holding brake, air suspension chassis with kneeling function. In the model these operations lead to a trigger signal for the air compressor control model. Above 10 bar the air compressor is active during braking. The kinetic energy of the bus is directly used to propel the air compressor. Below 10 bar the air compressor is also working in standstill. That means that all modes with "+AirComp" are either used during braking or at standstill. The modes with "Off" indicate modes at standstill. The mode "boost" is used when both motors are active to gain maximum power.

To compare the TIOM concept with a conventional electrical bus a reference case was defined. This reference case has one large motor with a power rating of $230 \mathrm{~kW}$. The auxiliaries like both compressors have their own electric drive which are modeled with typical values from manufacturer data.

\section{RESUlts}

The overall power rating of both motors together has been defined as $230 \mathrm{~kW}$. The energy reduction potential is very much dependent on the ratio between EMI and EMII. For this purpose, a parameter analysis was conducted. To determine the energy saving potential of the TIOM concept was compared with the reference case with one large motor. The different power ratios and the respective power breakdowns are visualized in figure 8 .

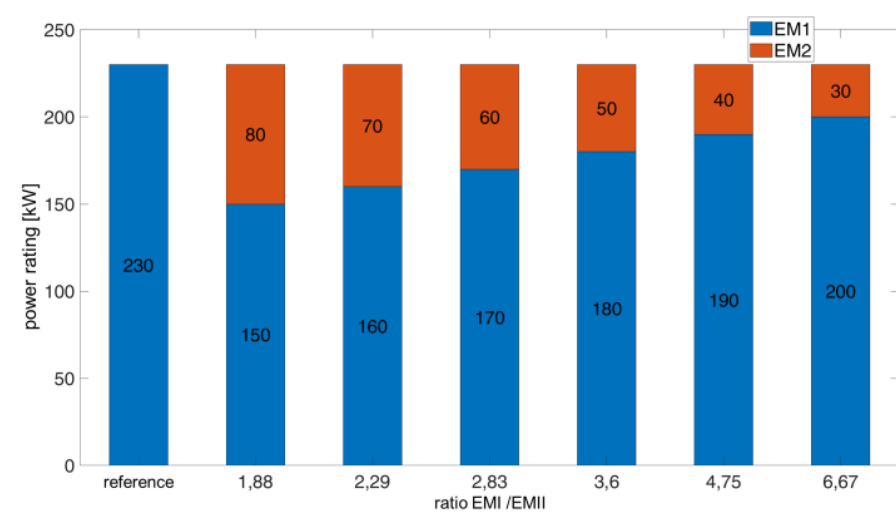

Fig. 8: Different power ratios for EMI and EMII

In Fig. 9 the energy savings of the TIOM concept as a function of the power ratio is shown for the case with deactivated AC system. It is evident, that with a power ratio of 4.75 the complete system has the highest energy saving potential of $3.02 \%$ compared to the reference case. This would mean a power breakdown of $190 \mathrm{~kW}$ for EMI and $40 \mathrm{~kW}$ for EMII. With a power ratio of 1.88 the energy consumption with the TIOM concept is even higher compared to the reference case, because EMII is working in partial load with lower efficiencies during steady-speed areas.

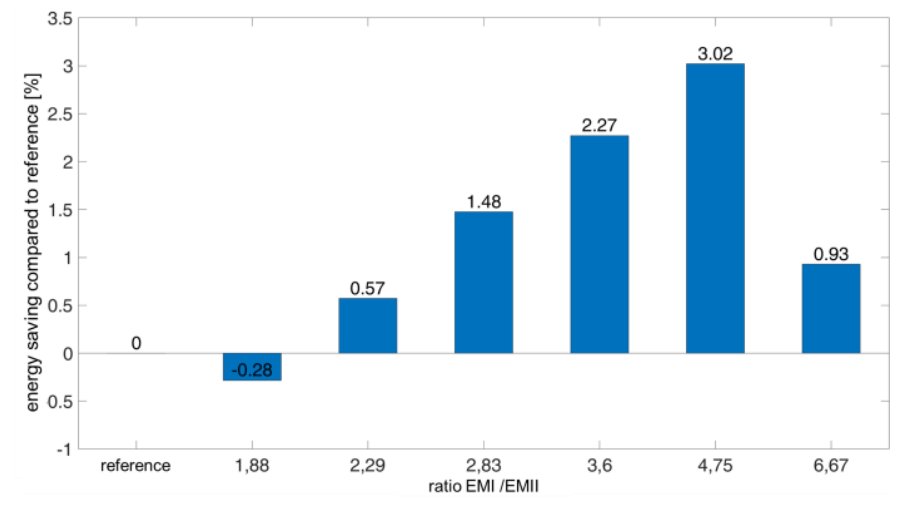

Fig. 9: Energy saving compared to reference with deactivated AC system

In figure 10 the energy savings are shown for different power ratios with activated AC system. The results show nearly the same pattern as in figure 9 . The overall efficiency increases up to a ratio of 4.75. Afterwards it decreases in both cases. With higher power ratios the power rating of EMII is too low to provide enough power for steady-speed. EMI therefore has to work in partial load with low efficiencies. It also turned out, that nearly one third of the operation time the bus is at standstill and only the air compressor and the AC compressor are active. That is the reason, why larger power ratings of EMII and therefore lower power ratios yield to lower energy savings as the operation points of EMII during standstill move to lower efficiencies.

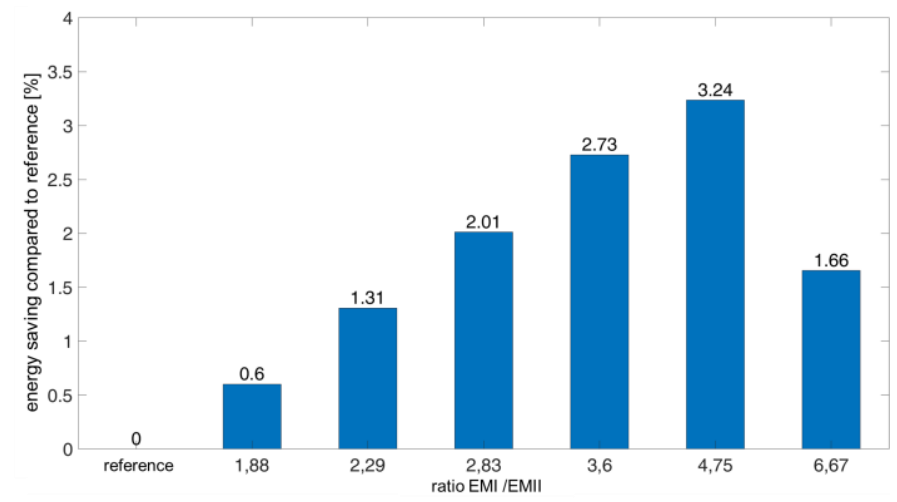

Fig. 10: Energy saving compared to reference with activated AC system

To summarize it up, EMI is mainly used for accelerating and braking. EMII for stead-speed and standstill periods. The boost mode is only used in less than $2 \%$ of the cycle time. The energy savings are coming from higher efficiencies of the motors and also the fact that part of the kinetic energy can be used to propel the air compressor during braking. The control strategy of the air compressor is sufficient to hold the pressure level in the air reservoir within the defined range at all times.

For the chosen power ratio of 4.75 in figure 11 the operation points of EMI are shown with a power rating of $190 \mathrm{~kW}$. The SORT2 cycle defines accelerating and 
braking curves with constant acceleration/deceleration, therefore these curves draw constant lines in the characteristic diagram. It is evident, that EMI is mostly used for accelerating and braking phases, like it was assumed in the operation strategy.

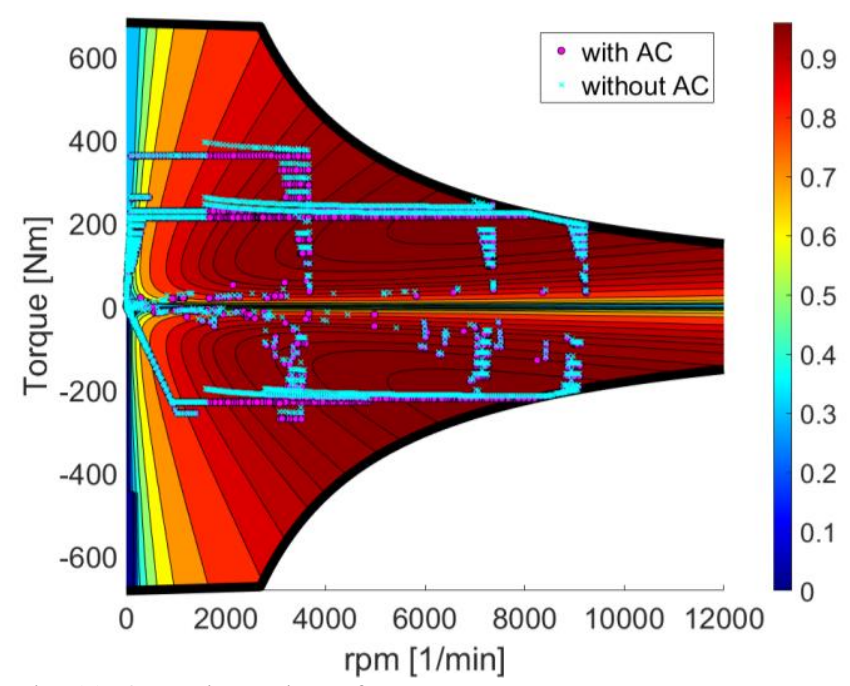

Fig. 11: Operation points of EMI

Analogues in figure 12 the operation points of EMII with a power rating of $40 \mathrm{~kW}$ are shown. It can be seen, that EMII is often used in standstill for the AC system. It is also evident, that EMII is often used for smaller power requests and steady-speed phases, like it was assumed in the operation strategy.

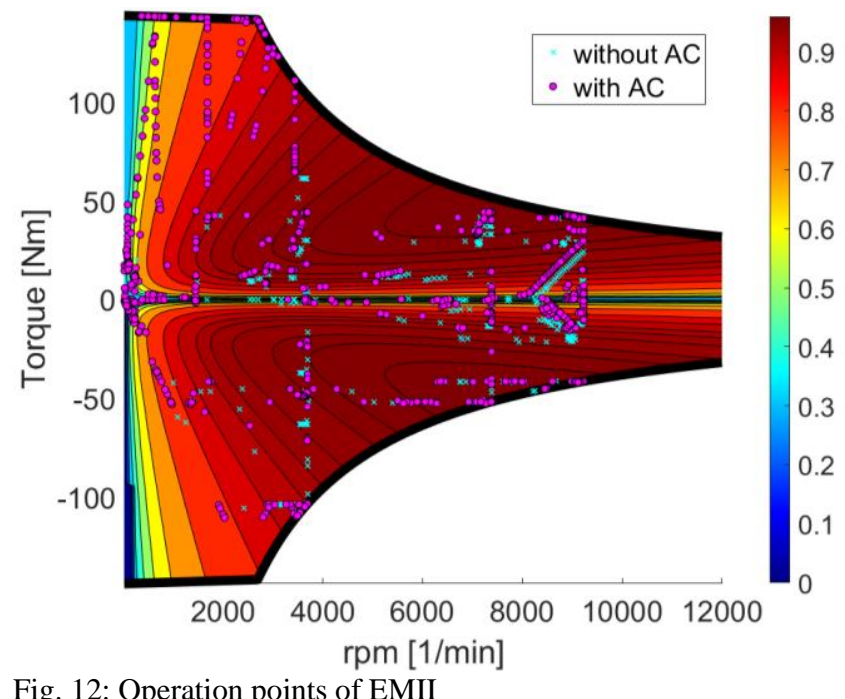

Fig. 12: Operation points of EMII
Looking on the time shares of the operation modes it turns out, that in the case of deactivated AC system EMI is active in $48.7 \%$ of the time, whereas EMII is active in $27.1 \%$ of the time. In the case of an activated AC system the share of EMI moves slightly to $48.6 \%$. The share of EMII therefore moves up to $53.2 \%$.

\section{CONCLUSION}

To sum it up, the TIOM concept is not only suitable for busses it also yields to high energy savings in typical driving cycles. The most suitable energy architecture seems to be to integrate the air compressor and the AC compressor into the TIOM concept. In the considered use case a parameter variation leads to an optimized power ratio of 4.75 of both motors that yields to an energy saving potential of up to $3.24 \%$. The introduced operation strategy is able to meet the defined requirements.

\section{REFERENCES}

[1] S. Kumar, M. Schier: "Increasing efficiency of ecological vehicles by integrating auxiliary units directly to the traction shaft", International conference of ecological vehicles and renewable energies EVER14, Monte Carlo, Monaco, 2014

[2] M. Schier, S. Kumar: "Design of a 2 in 1 Motor to increase the Efficiency of Electric Vehicles", International conference of ecological vehicles and renewable energies EVER15, Monte Carlo, Monaco, 2015.

[3] M. Hubner, M. Schier, N. Kevlishvili, A. Dietz, S. Hörlein: "Methodical approach for designing electric propulson systems containing two motors", International conference of ecological vehicles and renewable energies EVER17, Monte Carlo, Monaco, 2017

[4] S. Sigle, M. Schier: "Potential of a Two Motor Concept for Electric Vehicles with Respect to its Integration with the Air Conditioning Unit", Electric Vehicles International Conference \& Show EV2019, Bukarest, Romania, 2019

[5] Sigle, Sebastian und Epple, Fabius und Schier, Michael (2020) Investigation of the Applicability of a Two-Engine Concept for Electric Utility Vehicles.Fifteenth International Conference on Ecological Vehicles and Renewable Energies (EVER), 10.12.09.2020, Monte-Carlo, Monaco

[6] VDV - Verband Deutscher Verkehrsunternehmen. VDV-Statistik 2019, 2020. URL:https://www.vdv.de/statistik-jahresbericht.aspx

[7] Ralph Pütz. Einführung in die Linienbustechnik. ÖPNV-Wissen. Alba, Düsseldorf, 2012.

[8] EvoBus GmbH. Der neue eCitaro. Technische Information., 2019. URL https://www.mercedes-benz-bus.com.

[9] ZF Press Center, Elektrischer Zentralantrieb für den ÖPNV: ZF CeTrax geht in Serie, May 18th, 2020, URL: https://press.zf.com/press/de/releases/release_16643.html

[10] The International Association of Public Transport UITP, UITP project 'SORT' Standardised on-road test cycles, International Association of Public Transport, 2014. 